\title{
Nicotinic Cholinergic Receptors in the Rat Cerebellum: Multiple Heteromeric Subtypes
}

\author{
Jill R. Turner and Kenneth J. Kellar \\ Department of Pharmacology and Interdisciplinary Program in Neuroscience, Georgetown University, Washington, DC 20057
}

\begin{abstract}
Nicotinic receptors (nAChRs) in the cerebellum have been implicated in the pathology of autism spectrum disorders (Lee et al., 2002; Martin-Ruiz et al., 2004). The subtypes of nAChRs in the cerebellum are not known in any detail, except that, in addition to the homomeric $\alpha 7$ subtype, there appears to be one or more heteromeric subtypes consisting of combinations of $\alpha$ and $\beta$ subunits. To begin to better understand the potential roles of these heteromeric nAChRs in cerebellar circuitry and their potential as targets for nicotinic drugs, we investigated their subunit composition. Using subunit-selective antibodies in sequential immunoprecipitation assays, we detected six structurally distinct heteromeric $\mathrm{nAChR}$ populations in the rat cerebellum. Among these were several subtypes that have not been encountered previously, including $\alpha 3 \alpha 4 \beta 2$ and $\alpha 3 \alpha 4 \beta 4 \mathrm{nAChRs.} \mathrm{This} \mathrm{diversity} \mathrm{suggests} \mathrm{that} \mathrm{nAChRs} \mathrm{play} \mathrm{multiple} \mathrm{roles} \mathrm{in} \mathrm{cerebellar}$ physiology.
\end{abstract}

Key words: nicotinic receptor; acetylcholine; cerebellum; rat; receptor; antibody

\section{Introduction}

Neuronal nicotinic cholinergic receptors (nAChRs) are crucial to acetylcholine neurotransmission in both the CNS and autonomic nervous system. They mediate the fast excitatory signaling found in virtually all autonomic and sensory ganglia. In the CNS, however, these receptors are more often associated with modulation of release of several neurotransmitters including dopamine, norepinephrine, GABA, and glutamate (Wonnacott, 1997; Girod and Role, 2001). nAChRs have been implicated in the pathology and/or treatment of several neurological disorders including Alzheimer's disease, Parkinson's disease, Tourette's syndrome (for review, see Lindstrom, 1997), nicotine addiction (Mansvelder and McGehee, 2002), and recently, in autism disorders (Perry et al., 2001; Lee et al., 2002; Granon et al., 2003).

nAChRs are comprised of $\alpha$ and $\beta$ subunits that form a pentameric structure surrounding an ion channel. After activation by acetylcholine, the channel opens, allowing passage of sodium and calcium ions into the cell and potassium ions out of the cell. These receptors exist as subtypes based on their subunit compositions. Nine $\alpha$ subunits $(\alpha 2-\alpha 10)$ and three $\beta$ subunits $(\beta 2-\beta 4)$ are expressed in vertebrate systems and are relatively well conserved across most species (the $\alpha 8$ subunit is an exception). The most frequently encountered nAChRs in the CNS are the heteromeric $\alpha 4 \beta 2^{\star}$ subtype and the homomeric $\alpha 7$ subtype, whereas in the autonomic nervous system, the $\alpha 3 \beta 4^{\star}$ subtype is thought to pre-

Received May 25, 2005; revised Aug. 19, 2005; accepted Aug. 27, 2005.

This work was supported by National Institutes of Health (NIH) Grant DA12976 and NIH Training Grant 3T32NS041231-03S1. We thank Dr. Yingxian Xiao and Maryna Baydyuk for help with the mRNA measurements and Drs. Scott Rogers and Lorise Gahring (University of Utah, Salt Lake City, UT) for providing us with antisera to the $\alpha 2$, $\alpha 4, \alpha 5, \beta 3$, and $\beta 4 \mathrm{nAChR}$ subunits. We also thank Drs. Barry B. Wolfe and Robert P. Yasuda for helpful discussions and for providing us with antisera to $\alpha 3$ and $\alpha 6$.

Correspondence should be addressed to Kenneth J. Kellar, Department of Pharmacology, Georgetown University School of Medicine, 3900 Reservoir Road, Washington, DC 20057. E-mail: kellark@georgetown.edu.

DOI:10.1523/JNEUROSCI.2112-05.2005

Copyright $\odot 2005$ Society for Neuroscience $\quad$ 0270-6474/05/259258-08\$15.00/0 dominate (the ${ }^{*}$ is used to indicate that other, unidentified, subunits may also be incorporated in the receptor). However, other subtypes also play crucial roles in the nervous system. For example, receptors containing $\alpha 6$ and $\beta 3$ subunits appear to mediate a significant fraction of nicotine-stimulated dopamine and norepinephrine release (Champtiaux et al., 2002; Cui et al., 2003).

In the cerebellum, nAChRs mediate the release of glutamate (Reno et al., 2004), GABA (De Filippi et al., 2001; Rossi et al., 2003), and norepinephrine (O'Leary and Leslie, 2003). Thus, these receptors may significantly influence activity within the cerebellar circuitry, and dysregulation of this activity could contribute to developmental disorders involving the cerebellum. For example, aberrations in the relative distributions of cerebellar nAChRs have been described in autism (Court et al., 2000; Lee et al., 2002; Martin-Ruiz et al., 2004), suggesting that these receptors may play a role in this developmental disorder and/or that they may be potential therapeutic targets.

The subtypes of nAChRs in the cerebellum are not known in any detail except that, in addition to the homomeric $\alpha 7$ subtype, there appears to be one or more heteromeric subtypes, consisting of $\alpha$ and $\beta$ subunits. To begin to better understand the potential roles of these heteromeric nAChRs in cerebellar circuitry, we investigated their subunit composition in the rat cerebellum. To do this, we used subunit-selective antibodies in sequential immunoprecipitation assays. We detected six structurally distinct heteromeric $\mathrm{nAChR}$ populations in the rat cerebellum, including several subtypes that have not been encountered previously.

\section{Materials and Methods}

Materials. Frozen brains from Sprague Dawley rats $(\sim 250 \mathrm{~g})$ were purchased from Zivic Miller Laboratories (Portersville, PA). [ $\left.{ }^{3} \mathrm{H}\right]$ Epibatidine $\left(\left[{ }^{3} \mathrm{H}\right] \mathrm{EB}\right)$ and $\left[{ }^{125} \mathrm{I}\right] 5$-iodo-3(2(S)-azetidinylmethoxy)pyridine $\left(\left[{ }^{125} \mathrm{I}\right] \mathrm{A}-85380\right)$ were obtained from PerkinElmer (Boston, MA). Dihydro- $\beta$-erythroidine (DH $\beta E$ ) was from Research Biochemicals International (Natick, MA). Nicotine tartrate, cytisine, A-85380, and other chemicals were purchased from Sigma (St. Louis, MO), unless otherwise 
noted. Rabbit antisera directed at a bacterially expressed fusion protein containing partial sequences of the cytoplasmic domains of nAChR $\alpha 2$, $\alpha 4, \alpha 5, \beta 3$, and $\beta 4$ subunits were kind gifts from Drs. Scott Rogers and Lorise Gahring (University of Utah, Salt Lake City, UT). These antisera have been described previously (Flores et al., 1992; Rogers et al., 1992). An antibody directed at a peptide sequence of the rat $\mathrm{nAChR} \alpha 3$ subunit was affinity purified from rabbit serum. This antibody has been described previously (Yeh et al., 2001). A monoclonal antibody (mAb 270) to the chick $\beta 2$ subunit was made from hybridoma stocks (American Type Culture Collection, Manassas, VA). This mAb was originally developed and characterized by Whiting and Lindstrom (1987). Protein G-Sepharose beads were purchased from Amersham Biosciences (Piscataway, NJ). Protein A (Pansorbin) and normal rabbit serum (NRS) were purchased from Calbiochem (La Jolla, CA). For simplicity, in this paper, we use the term antibody to refer to unpurified antisera, as well as to affinity-purified antiserum and monoclonal antibody.

Receptor binding. Tissues were homogenized in $50 \mathrm{~mm}$ Tris $\mathrm{HCl}$ buffer, $\mathrm{pH} 7.4$ at $24^{\circ} \mathrm{C}$, and centrifuged twice at $35,000 \times \mathrm{g}$ for $10 \mathrm{~min}$ in fresh buffer. The membrane pellets were resuspended in fresh buffer and added to tubes containing $\left[{ }^{3} \mathrm{H}\right] \mathrm{EB}$ or $\left[{ }^{125} \mathrm{I}\right] \mathrm{A}-85380$ with or without competing drugs. Incubations were performed in Tris buffer at $\mathrm{pH} 7.4$ for $2 \mathrm{~h}$ at $24^{\circ} \mathrm{C}$ with $\left[{ }^{3} \mathrm{H}\right] \mathrm{EB}$ and $\left[{ }^{125} \mathrm{I}\right] \mathrm{A}-85380$. Bound receptors were separated from free ligand by vacuum filtration over GF/C glass-fiber filters (Brandel, Gaithersburg, MD) that were prewet with $0.5 \%$ polyethyleneimine, and the filters were then counted in a liquid scintillation counter. Nonspecific binding was determined in the presence of $300 \mu \mathrm{M}$ nicotine, and specific binding was defined as the difference between total binding and nonspecific binding.

mRNA measurements. Total cellular RNA was isolated using RNASTAT-60 (Tel-Test B, Friendswood, TX). DNA templates for antisense riboprobes were prepared as described previously (Xiao et al., 1998). Antisense riboprobes for the $\alpha 2-\alpha 7$ and $\beta 2-\beta 4 \mathrm{nAChR}$ subunits were generated from DNA templates using T7 RNA polymerase and $\left[\alpha-{ }^{32} \mathrm{P}\right] \mathrm{CTP}$. The RNase protection assays were performed using the RPA II kit (Ambion, Austin, TX). Total RNA $(20 \mu \mathrm{g})$ from the tissue samples was hybridized overnight at $42^{\circ} \mathrm{C}$ with the subunit riboprobes and a riboprobe for rat glyceraldehyde-3-phosphate dehydrogenase (GAPDH), which was used as an internal and loading control. After hybridization, nonprotected fragments were digested with a combination of RNase A and RNase $\mathrm{T} 1 \mathrm{for} 30 \mathrm{~min}$ at $37^{\circ} \mathrm{C}$. The numbers of bases of the full-length probes and the protected fragments of the probe were as follows: $\alpha 2,416$ and 332; $\alpha 3,306$ and $230 ; \alpha 4,496$ and $408 ; \alpha 5,411$ and $380 ; \alpha 6,462$ and $396 ; \alpha 7,450$ and 376 ; $\beta 2,322$ and $263 ; \beta 3,430$ and 394; $\beta 4,252$ and 170 ; and GAPDH, 204 and 135 . The protected probe fragments were separated by electrophoresis on a $6 \%$ denaturing polyacrylamide gel, and the fragments were visualized on $\mathrm{x}$-ray film or with a phosphorimager.

Immunoprecipitation. Tissue membrane homogenates were prepared as above for binding assays. The receptors were solubilized by incubating the homogenates in $2 \%$ Triton X-100 with gentle rotation for $2 \mathrm{~h}$ at room temperature. After centrifuging the mixture at $35,000 \times g$ for $10 \mathrm{~min}$, aliquots of the clear supernatant (equivalent to $9 \mathrm{mg}$ of original tissue weight) were added to sample tubes containing $\left[{ }^{3} \mathrm{H}\right] \mathrm{EB}$ and either one of the subunit-specific antibodies at a concentration determined in preliminary studies to be optimal for each or an equivalent volume of NRS. The samples were then rotated overnight at $4^{\circ} \mathrm{C}$. After the addition of $50 \mu \mathrm{l}$ of a $50 \%$ slurry of protein G-Sepharose beads or a $12 \%$ slurry of Pansorbin (source of protein A), the rotation of the samples at $4^{\circ} \mathrm{C}$ was continued for $1 \mathrm{~h}$. The samples were then centrifuged at $\sim 7000 \times g$ for $5 \mathrm{~min}$, and the supernatants were removed and placed on ice for later use in sequential immunoprecipitation studies. The remaining tissue pellets were washed once with $1 \mathrm{ml}$ of $50 \mathrm{~mm}$ Tris $\mathrm{HCl}$ buffer, $\mathrm{pH}$ 7.0, dissolved in $1 \mathrm{~N}$ $\mathrm{NaOH}$, and then counted in a scintillation counter. After subtracting the number of counts precipitated in tubes containing NRS, the number of $\left[{ }^{3} \mathrm{H}\right]$ EB-labeled nAChRs immunoprecipitated by each antibody was compared with the total number of labeled receptors, as measured in samples of the solubilized cerebellar membranes before addition of the antibodies.

Sequential immunoprecipitation assays. To determine associations between subunits, we used a sequential immunoprecipitation assay. This or conceptually similar methods have been used previously to determine the predominant nAChR subtypes in several other neuronal tissues including chick ciliary ganglia, retina, and brain (Conroy et al., 1992; Vernallis et al., 1993; Conroy and Berg, 1998; Vailati et al., 2003), rat brain (Flores et al., 1992; Zoli et al., 2002), rat trigeminal ganglia (Flores et al., 1996), rat pineal gland (Hernandez et al., 2004), and most recently, the rat retina (Moretti et al., 2004; Marritt et al., 2005). Thus, the sequential immunoprecipitation approach to determine subunit composition has been found to be useful in a large number of tissues, but each tissue may present its own specific challenges, depending on the number of receptor subunits and subtypes present and their relative abundance.

In this assay, the clear supernatant remaining after immunoprecipitation with the first antibody or NRS was incubated with a different subunit-selective antibody, and the immunoprecipitation steps with protein $G$ or protein A were then repeated, as described above. The rationale for this procedure is that if two subunits are associated in a $\mathrm{nAChR}$, antibodies to either subunit will immunoprecipitate that receptor and the resultant supernatant will contain fewer receptors to be immunoprecipitated by the antibody directed at the second subunit. In control studies, the number of solubilized nAChRs measured with $\left[{ }^{3} \mathrm{H}\right] \mathrm{EB}$ was stable when incubated in the absence of an antibody over the time course of the sequential immunoprecipitation procedure.

Data analysis. Binding data were fit to one- and two-site models using the GraphPad Prism 4.0 software package (GraphPad Software, San Diego, CA). A one-sample $t$ test was used in drug binding competition assays to determine whether the Hill coefficients were different from 1 and in immunoprecipitation assays to determine whether residual values were different from 0 . The propagation of error method (Bevington, 1969) was used to calculate the SEM for the difference between groups and for comparing the sum of subtypes to the total number of nAChRs in the cerebellum. Statistical analyses of the differences between groups were assessed using one-way ANOVA followed by Bonferroni's multiple comparison test.

\section{Results \\ Binding of $\left[{ }^{3} \mathrm{H}\right] \mathrm{EB}$ and $\left[{ }^{125} \mathrm{I}\right] \mathrm{A}-85380$ to nicotinic receptors in the rat and human cerebellum}

Saturation binding experiments using $\left[{ }^{3} \mathrm{H}\right] \mathrm{EB}$ and $\left[{ }^{125} \mathrm{I}\right] \mathrm{A}$ 85380 were performed with cerebellum homogenates. Epibatidine is a broad-spectrum nAChR ligand that binds with very high affinity (25-300 pM) to all known heteromeric nAChRs (Houghtling et al., 1995; Parker et al., 1998; Xiao and Kellar, 2004). In contrast, $\left[{ }^{125} \mathrm{I}\right] \mathrm{A}-85380$ binds selectively to $\beta 2$ containing nAChRs (Mukhin et al., 2000; Xiao and Kellar, 2004). Therefore, examination of the $\mathrm{nAChR}$ binding sites labeled by these two ligands helps to distinguish between the nAChRs that contain $\beta 2$ subunits from the total population of receptors (i.e., those that that contain $\beta 2$ and/or $\beta 4$ subunits). As shown in Figure 1, the density of cerebellar $\mathrm{nAChR}$ binding sites measured with $\left[{ }^{125} \mathrm{I}\right] \mathrm{A}-85380$ is $\sim 67 \%$ of the density measured with $\left[{ }^{3} \mathrm{H}\right] \mathrm{EB}$. These data suggest that approximately two-thirds of the nAChR binding sites in the cerebellum contain $\beta 2$ subunits (those labeled by both $\left[{ }^{3} \mathrm{H}\right] \mathrm{EB}$ and $\left[{ }^{125} \mathrm{I}\right] \mathrm{A}-85380$ ), and onethird contain $\beta 4$ subunits (those labeled by $\left[{ }^{3} \mathrm{H}\right] \mathrm{EB}$ only).

The inset to Figure 1 shows the relative binding of a single saturating concentration of $\left[{ }^{3} \mathrm{H}\right] \mathrm{EB}$ and $\left[{ }^{125} \mathrm{I}\right] \mathrm{A}-85380$ in both the rat and human cerebellum. These data indicate that the overall nAChR density is similar in the rat and human cerebellum and also suggest that $\left[{ }^{3} \mathrm{H}\right] \mathrm{EB}$ binds more sites than $\left[{ }^{125} \mathrm{I}\right] \mathrm{A}-85380$.

\section{Drug competition for $\left[{ }^{3} \mathrm{H}\right] \mathrm{EB}$ binding sites in the cerebellum}

In binding competition studies, we used several ligands that can differentiate between nicotinic receptor subtypes that contain $\beta 2$ and $\beta 4$ subunits, including A-85380 and I-A-85380. All of the ligands examined here competed for the nAChRs labeled by $\left[{ }^{3} \mathrm{H}\right] \mathrm{EB}$ in the cerebellum (Fig. 2). In all cases, the competition 


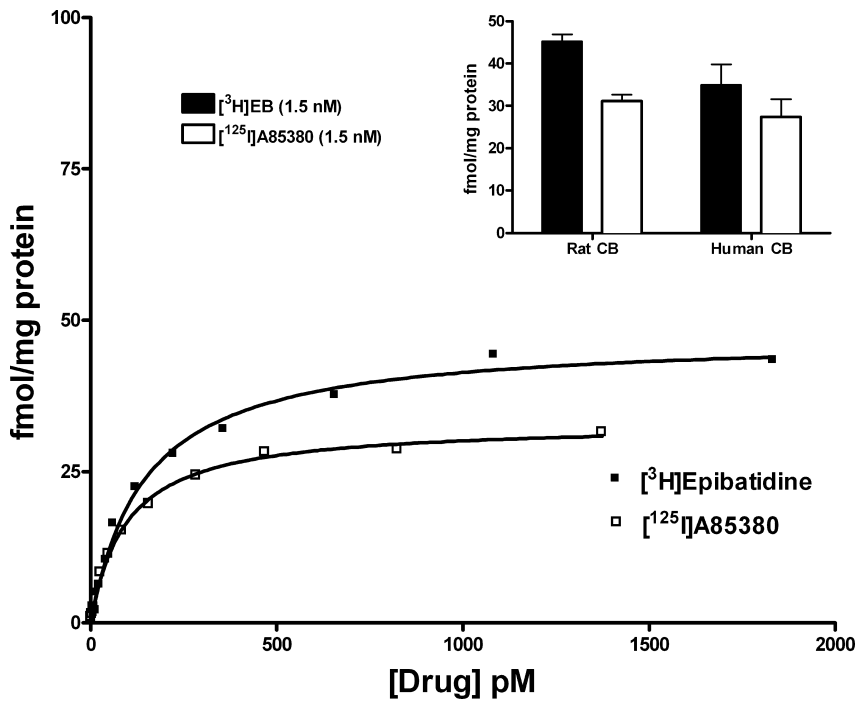

Figure 1. Binding of $\left[{ }^{3} \mathrm{H}\right] \mathrm{EB}$ and $\left[{ }^{125} \mathrm{~J}\right] \mathrm{A}-85380$ to membrane homogenates from rat and human cerebellum. Representative saturation binding curves of $\left[{ }^{3} \mathrm{H}\right] \mathrm{EB}$ and $\left[{ }^{125}\right] \mathrm{A}-85380$ binding to membrane homogenates of rat cerebellum are shown. The $B_{\max }$ values for $\left[{ }^{3} \mathrm{H}\right] \mathrm{EB}$ and [ $\left.{ }^{125} \mathrm{I}\right] \mathrm{A}-85380$ are $45 \pm 2$ and $30 \pm 1 \mathrm{fmol} / \mathrm{mg}$ protein, respectively. The $K_{\mathrm{d}}$ values for $\left[{ }^{3} \mathrm{H}\right] \mathrm{EB}$ and [ $\left.\left.{ }^{125}\right]\right] \mathrm{A}-85380$ are $119 \pm 21$ and $96 \pm 42 \mathrm{pm}$, respectively $(n=3)$. Inset, Specific binding of $\left[{ }^{3} \mathrm{H}\right] \mathrm{EB}$ and $\left[{ }^{125} \mathrm{I}\right] \mathrm{A}-85380$ at a single saturating concentration to membrane homogenates of rat and human cerebellum $(C B)$ to demonstrate the relative densities of the total $n A C h R$ population (measured with $\left[{ }^{3} \mathrm{H}\right] \mathrm{EB}$ ) and $\mathrm{nAChRs}$ containing $\beta 2$ subunits (measured with [ ${ }^{125}$ I]A-85380). Values are the mean \pm SEM from four human and four rat samples.

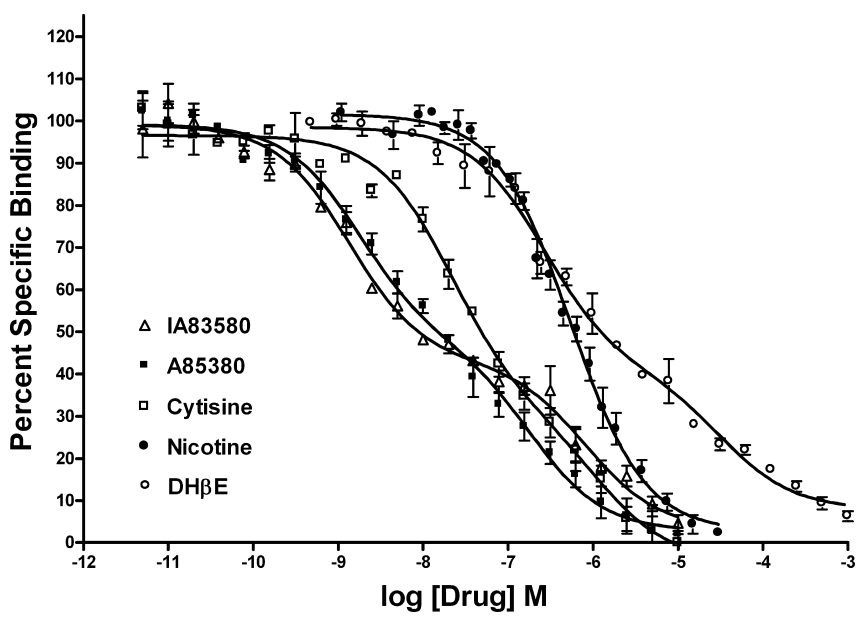

Figure 2. Competition by drugs for $\left[{ }^{3} \mathrm{H}\right] \mathrm{EB}$-labeled binding sites in membrane homogenates from rat cerebellum. The membrane homogenates were incubated with $1 \mathrm{~nm}\left[{ }^{3} \mathrm{H}\right] \mathrm{EB}$, and the competing drugs were added at the concentrations indicated. All curves were fit best by a two-site binding model. Data shown are the mean \pm SEM from three or four experiments. The $K_{\mathrm{i}}$ values, Hill slopes, and fraction of the high-affinity site are provided in Table 1.

curves were shallow (Hill slopes, $<1 ; p<0.02$ ), suggesting the presence of at least two classes of binding sites based on their affinities. Indeed, as summarized in Table 1, the curves fit best to a model for two classes of binding sites with $\sim 60 \%$ of the sites in the high-affinity class and $40 \%$ in the lower-affinity class. Together, these data indicate that the rat cerebellum contains at least two classes of nAChR binding sites, consistent with the presence of more than one receptor subtype.

\section{Nicotinic receptor subunit expression in the rat cerebellum}

We used RNase protection assays to detect the presence of nAChR subunit mRNA in the rat cerebellum. Of the nine nAChR
Table 1. Binding parameters at cerebellar nAChRs for the drugs shown in Figure 2

\begin{tabular}{lcclll}
\hline Ligand & $K_{\mathrm{i}} 1(\mathrm{~nm})$ & $K_{\mathrm{i}} 2(\mathrm{~nm})$ & Hill slope & \multicolumn{2}{l}{ Fraction of } \\
\hline I-A-85380 & 0.06 & 120 & $0.39 \pm 0.05$ & $61 \pm 3 \%$ & 3 \\
A-85380 & 0.07 & 24 & $0.47 \pm 0.08$ & $49 \pm 5 \%$ & 3 \\
Cytisine & 0.95 & 240 & $0.55 \pm 0.08$ & $69 \pm 5 \%$ & 4 \\
Nicotine & 8 & 363 & $0.83 \pm 0.02$ & $62 \pm 27 \%$ & 4 \\
DH $\beta$ E & 10 & 5700 & $0.41 \pm 0.03$ & $63 \pm 3 \%$ & 4 \\
\hline
\end{tabular}

$K_{\mathrm{i}}, K_{\mathrm{i}}$ for high-affinity site; $K_{\mathrm{i}}, K_{\mathrm{i}}$ for low-affinity site.

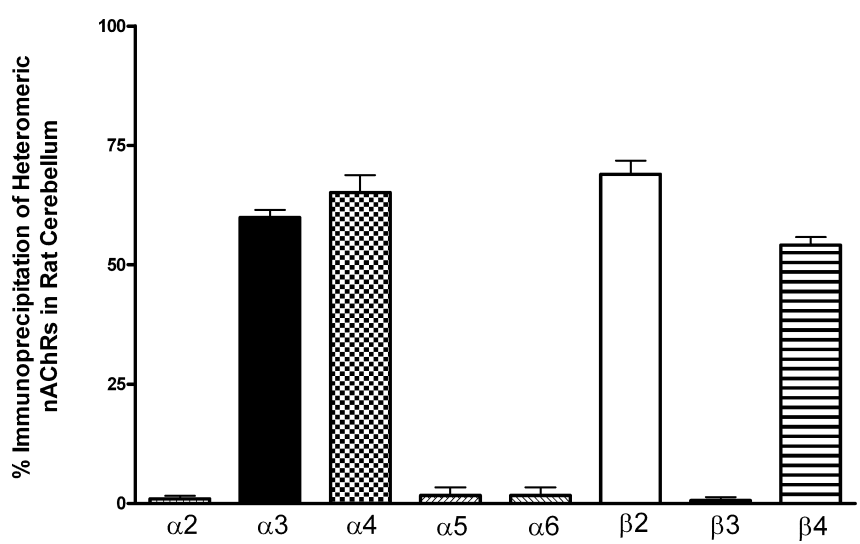

Figure 3. $n A C h R$ subunits detected by immunoprecipitation in the rat cerebellum. Rat cerebellum $n A C h R s$ were solubilized, labeled with $\left[{ }^{3} \mathrm{H}\right] \mathrm{EB}$, and incubated with each of the antibodies shown. Nonspecific immunoprecipitation was measured with normal rabbit serum and has been subtracted. Only the antibodies to the $\alpha 3, \alpha 4, \beta 2$, and $\beta 4$ subunits immunoprecipitated $\left[{ }^{3} \mathrm{H}\right] \mathrm{EB}$-labeled $n \mathrm{AChRs}$ from the rat cerebellum, indicating that all heteromeric $n A C h R s$ in the cerebellum are composed of combinations of these subunits. Data shown are mean \pm SEM of $3-13$ independent experiments.

subunits $(\alpha 2-\alpha 7$ and $\beta 2-\beta 4)$ examined using a multiplex assay, mRNA was found for only the $\alpha 3, \alpha 4$, and $\beta 2$ subunits (supplemental material, available at www.jneurosci.org). Previous studies have detected these subunits in the rat cerebellum (WinzerSerhan and Leslie, 1997; Nakayama et al., 1998; Zhang et al., 1998), and, in addition, the $\beta 4$ subunit was detected by in situ hybridization (Winzer-Serhan and Leslie, 1997). Although we did not detect the $\beta 4$ subunit mRNA transcripts in the cerebellum in our protection assays, we did detect them in parallel studies with the rat pineal gland and PC12 cells (data not shown). It is possible that the level of $\beta 4$ mRNA within the cerebellum is below the level of detection in our assay. In this regard, other nAChR subunits may also be expressed in low amounts, below our limits of detection.

Immunoprecipitation of $\mathrm{nAChRs}$ in the cerebellum

Because nAChR subtypes are defined by their subunit composition, we used highly selective antibodies directed at specific nAChR subunits to immunoprecipitate $\left[{ }^{3} \mathrm{H}\right]$ EB-labeled receptors solubilized from cerebellum homogenates.

Although we detected mRNA transcripts only for $\alpha 3, \alpha 4$, and $\beta 2$ subunits in the cerebellum, nAChRs might also be on axons originating outside of the cerebellum; therefore, we tested for the presence of nAChRs containing $\alpha 2-\alpha 6$ subunits and $\beta 2-\beta 4$ subunits in our immunoprecipitation assays. The results indicate that the adult rat cerebellum expresses receptors containing $\alpha 3$, $\alpha 4, \beta 2$, and $\beta 4$ subunits, but any receptors containing $\alpha 2, \alpha 5, \alpha 6$, or $\beta 3$ subunits were undetectable (Fig. 3). The $\alpha 3, \alpha 4, \beta 2$, and $\beta 4$ subunits often form two major classes of subtypes, as defined primarily by their pharmacological characteristics: $\alpha 3 \beta 4^{\star}$ and 


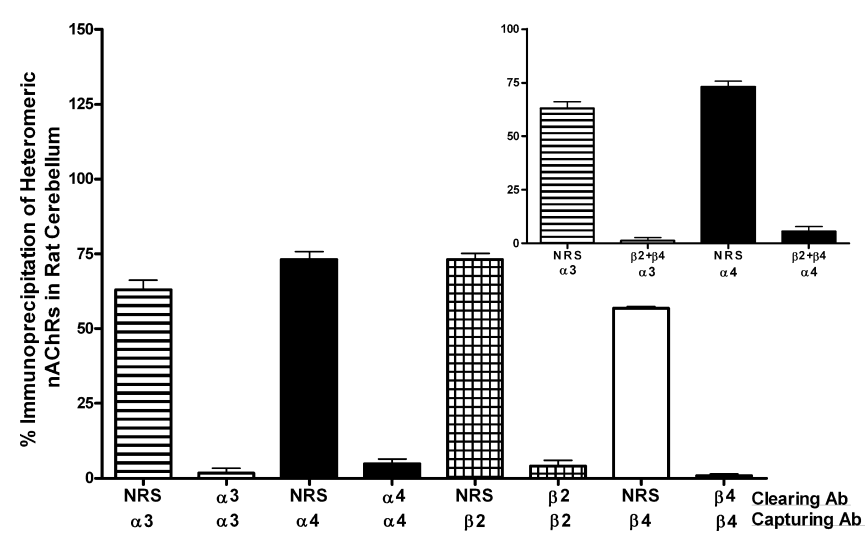

Figure 4. Completeness of immunoprecipitation of nAChRs in rat cerebellum. Sequential immunoprecipitation of cerebellar $n A C h R s$ with the antibodies shown was performed using the same antibody in the first (clearing) and the second (capturing) immunoprecipitation. Comparisons were made to samples in which the first immunoprecipitation was performed with NRS followed by immunoprecipitation with each of the antibodies. The bars represent the percentage of the total number of $\left[{ }^{3} \mathrm{H}\right] \mathrm{EB}$-labeled $n A C h R s$ in the cerebellum immunoprecipitated by the capturing antibody and are the mean \pm SEM from three or four experiments. This study demonstrates that the concentrations of antibodies used immunoprecipitated essentially all of the $n A C h R s$ that contain the cognate subunit. Inset, To test the assumption that all nAChRs contain $\beta 2, \beta 4$, or both subunits, cerebellum tissue samples were first immunoprecipitated (cleared) with antibodies to both the $\beta 2$ and $\beta 4$ subunits in the same test tube, and the resulting supernatant was then subjected to a second immunoprecipitation with a capturing antibody directed at either the $\alpha 3$ or $\alpha 4$ subunit. As shown, the initial immunoprecipitation with the two $\beta$ subunit antibodies cleared virtually all $\mathrm{nAChRs}$ in the sample, demonstrating that all heteromeric $n A C h R s$ contain $\beta 2$ and/or $\beta 4$ subunits.

$\alpha 4 \beta 2^{\star}$. However, as shown in Figure 3, our immunoprecipitation studies indicated that the percentage of $\alpha 3$ - and $\alpha 4$-containing nAChRs (60 and 65\%, respectively) and the percentage of $\beta 2$ and $\beta 4$-containing nAChRs (70 and 55\%, respectively) each exceed $100 \%$ of the total number of nAChRs in the cerebellum $(p<$ $0.01)$. This suggests that the cerebellum contains one or more mixed heteromeric receptor subtypes (i.e., receptors containing the two different $\alpha$ and/or the two different $\beta$ subunits associated in one complex). Sequential immunoprecipitation assays provide a direct method for examining subunit composition.

\section{Basis for sequential immunoprecipitation method}

This procedure is based on the observation that $\left[{ }^{3} \mathrm{H}\right] \mathrm{EB}$ binds to assembled $\alpha$ and $\beta$ subunit combinations, which represent potential heteromeric nAChRs, but it does not bind to $\alpha$ subunits that are not associated with a $\beta$ subunit partner or vice versa (Xiao et al., 1998; Xiao and Kellar, 2004). Therefore, once the presence of a particular $\mathrm{nAChR}$ subunit is established with an antibody in the first immunoprecipitation assay, the subunit(s) it is associated with can be determined by performing a second immunoprecipitation on the resultant supernatant with a different antibody. The rationale for this sequential procedure is that if two (or more) different subunits are part of the same receptor, then initial immunoprecipitation of that receptor with an antibody directed at one subunit (the clearing antibody) will decrease the amount of the receptor available in the remaining supernatant of the sample for immunoprecipitation with a subsequent antibody (the capturing antibody) directed at the second subunit (Flores et al., 1992; Hernandez et al., 2004). Sequential immunoprecipitation can thus demonstrate the direct association of two nAChR subunits.

To test whether the antibodies we used immunoprecipitated all the receptors containing their cognate subunits, we performed sequential immunoprecipitation studies using the same antibody

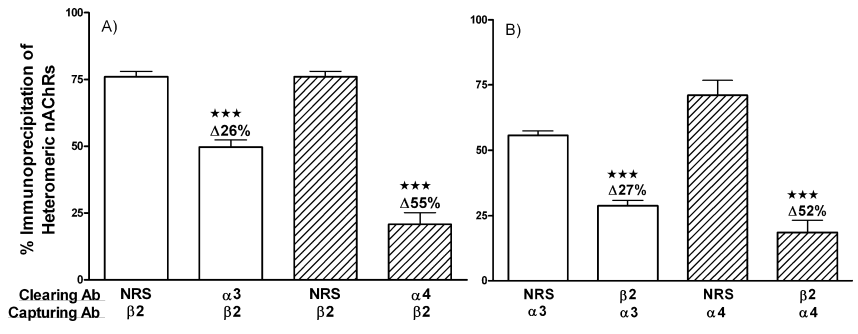

Figure 5. Sequential immunoprecipitation of $n A C h R s$ in rat cerebellum: association with $\beta 2$ subunits. $\boldsymbol{A}$, Samples were first cleared with NRS as a control or antibodies directed at either the $\alpha 3$ or $\alpha 4$ subunit; the resulting supernatant was then immunoprecipitated with the antibody to the $\beta 2$ subunit. $\boldsymbol{B}$, To confirm the results in $\boldsymbol{A}$, the order of antibodies was reversed. That is, after first clearing the sample with NRS (control) or antibodies to the $\beta 2$ subunit, the resultant supernatant was immunoprecipitated with antibodies to the $\alpha 3$ or $\alpha 4$ subunits. The bars represent the percentage of the total number of $\left[{ }^{3} \mathrm{H}\right] \mathrm{EB}$-labeled $n A C h R s$ immunoprecipitated by the capturing antibody and are the mean \pm SEM of 7-10 experiments. The values above the bars are the percentage reduction of total cerebellar nAChRs resulting from clearing with the indicated antibody compared with the corresponding value after clearing with NRS. Different from corresponding NRS control, ${ }^{* *} p<0.001$.

in both the clearing and capturing steps (e.g., $\beta 2$ followed by $\beta 2$ ) and compared the results to parallel studies in which NRS instead of the specific antibody was used in the clearing step. Incubation of cerebellar extracts with NRS in the clearing step did not affect the immunoprecipitation by any of the antibodies, and each immunoprecipitated a similar percentage of nAChRs as it had in the single immunoprecipitation studies (compare Figs. 3, 4). In contrast, when each antibody was used in the clearing step, it removed nearly all of the nAChRs containing its cognate subunit, so there were essentially no nAChRs containing that subunit remaining in the supernatant to be immunoprecipitated by the same antibody in the capturing step (Fig. 4).

All heteromeric nAChRs are assumed to contain either $\beta 2$ or $\beta 4$ subunits or both. We tested this assumption as well as the efficacy of the sequential immunoprecipitation procedure by incubating cerebellar extracts with both the $\beta 2$ and $\beta 4$ antibodies simultaneously in the clearing immunoprecipitation. The sequential method predicts that the second round of immunoprecipitation, performed on the resulting supernatant with a capturing antibody directed toward an $\alpha$ subunit, would find no nAChRs remaining in that supernatant. The results from this series of experiments are shown in the inset to Figure 4. After an initial incubation with NRS, the $\alpha 3$ and $\alpha 4$ antibodies immunoprecipitated $\sim 60$ and $70 \%$, respectively, of the nAChRs in the cerebellar extracts. In contrast, after concurrent exposure of the extracts to both the $\beta 2$ and $\beta 4$ antibodies, no significant immunoprecipitation with either the $\alpha 3$ or $\alpha 4$ antibodies was detected. These results strongly support the assumption that all heteromeric nAChRs in the cerebellum contain a $\beta 2$ and/or $\beta 4$ subunit and also demonstrate that the sequential immunoprecipitation method can quantitatively assess associations between different subunits.

\section{nAChR subunit associations in the rat cerebellum}

The sequential immunoprecipitation procedure was used to detect and quantify the association between subunits in nAChRs in the cerebellum. We first examined the associations between $\alpha$ and $\beta$ subunits and then examined associations between the two $\alpha$ subunits and between the two $\beta$ subunits.

\section{Associations with the $\beta 2$ subunit}

Results from sequential immunoprecipitation studies to examine the subunit associations with the $\beta 2$ subunit in the cerebellum are shown in Figure 5. Consistent with the studies shown in Figure 4, 


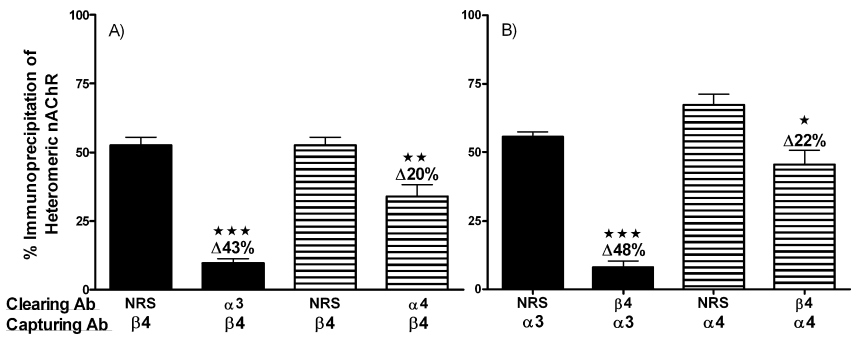

Figure 6. Sequential immunoprecipitation of $n A C h R s$ in rat cerebellum: association with $\beta 4$ subunits. $A$, Samples were first cleared with NRS as a control or antibodies directed at either the $\alpha 3$ or $\alpha 4$ subunit; the resulting supernatant was then immunoprecipitated with the antibody to the $\beta 4$ subunit. $\boldsymbol{B}$, To confirm the results in $\boldsymbol{A}$, the order of antibodies was reversed. That is, after first clearing the sample with NRS (control) or the antibody to the $\beta 4$ subunit, the resultant supernatant was immunoprecipitated with antibodies to the $\alpha 3$ or $\alpha 4$ subunits. The bars represent the percentage of the total number of $\left[{ }^{3} \mathrm{H}\right] \mathrm{EB}$-labeled $n A C h R s$ immunoprecipitated by the capturing antibody and are the mean \pm SEM of seven to nine experiments. The values above the bars are the percentage reduction of total cerebellar nAChRs resulting from clearing with the indicated antibody compared with the corresponding value after clearing with NRS. Different from corresponding NRS control, ${ }^{*} p<0.05,{ }^{* *} p<0.01{ }^{* * *} p<0.001$. In addition, all of the values for the residual receptors remaining after the capturing antibodies are different from $0(p<0.01)$.

antibodies to the $\beta 2$ subunit immunoprecipitated $\sim 75 \%$ of the nAChRs in the cerebellum, and this was unaffected by clearing with either NRS (Fig. 5A) or with an irrelevant monoclonal antibody (data not shown). In contrast, after the antibody directed at the $\alpha 3$ subunit was used in the clearing step, the $\beta 2$ antibody immunoprecipitated only $\sim 49 \%$ of the total heteromeric $\mathrm{nAChR}$ population in the cerebellum (Fig. $5 A$ ), indicating that $\sim 26 \%$ of the nAChRs in the cerebellum contain $\alpha 3$ subunits in association with $\beta 2$ subunits (i.e., they are $\alpha 3 \beta 2^{\star}$ receptors). Similarly, clearing with the $\alpha 4$ antibody reduced the number of cerebellar heteromeric nAChRs immunoprecipitated with the $\beta 2$ antibody to $20 \%$ (Fig. 5A), indicating that $\sim 55 \%$ are $\alpha 4 \beta 2^{\star}$ receptors.

To test the precision of the sequential immunoprecipitation method, we reversed the order of the antibodies; that is, we performed the first immunoprecipitation (the clearing step) with the $\beta 2$ antibody and the second immunoprecipitation (the capture step) with the $\alpha 3$ or $\alpha 4$ antibody. The results of these experiments are shown in Figure $5 B$. After clearing the cerebellar extracts with NRS, the $\alpha 3$ and $\alpha 4$ antibodies immunoprecipitated 56 and $71 \%$ of the nAChRs, respectively; whereas, after clearing with the $\beta 2$ antibody, the total number of cerebellar nAChRs immunoprecipitated with the $\alpha 3$ and $\alpha 4$ antibodies was decreased by 27 and 52\%, respectively. The consistency between the results obtained in the studies shown in Figure 5, $A$ and $B$, reinforces the degree of associations of the $\beta 2$ subunit with $\alpha 3$ and $\alpha 4$ subunits, and together, these results indicate that $\sim 26 \%$ of the nAChRs in the cerebellum are an $\alpha 3 \beta 2^{\star}$ subtype and $\sim 54 \%$ are an $\alpha 4 \beta 2^{\star}$ subtype.

\section{Associations with the $\beta 4$ subunit}

Similar sequential studies were performed to examine the subunit associations of the $\beta 4$ subunit with the $\alpha 3$ and $\alpha 4$ subunits. As shown in Figure $6 A$, after clearing the cerebellum extracts with NRS, the $\beta 4$ antibody immunoprecipitated $\sim 52 \%$ of the $\left[{ }^{3} \mathrm{H}\right]$ EB-labeled $\mathrm{nAChRs}$; in contrast, after clearing with the $\alpha 3$ antibody, the $\beta 4$ antibody immunoprecipitated only $\sim 9 \%$ of the remaining nAChRs in the extracts. These results indicate that $\sim 43 \%$ of the total heteromeric nAChRs in the cerebellum contain $\alpha 3$ subunits in association with $\beta 4$ subunits (i.e., they are $\alpha 3 \beta 4^{\star}$ subtypes). Likewise, clearing the cerebellar extracts with the $\alpha 4$ antibody decreased the subsequent immunoprecipitation by the $\beta 4$ antibody to $\sim 32 \%$, indicat-

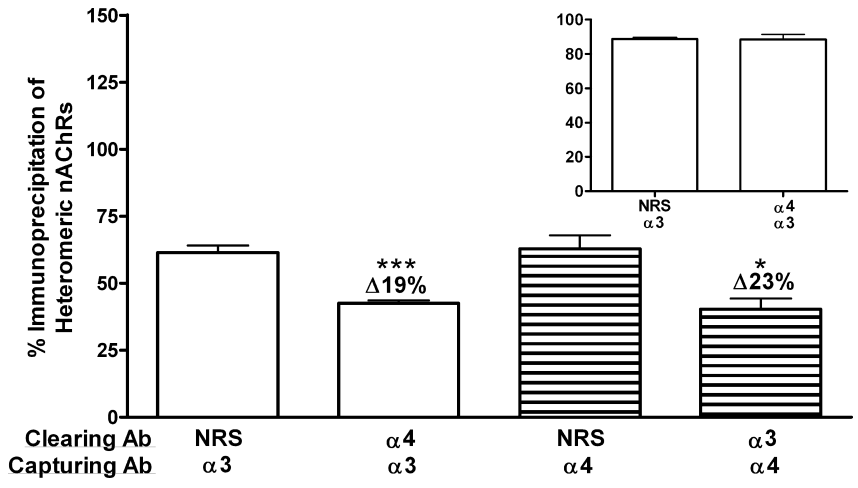

Figure 7. Sequential immunoprecipitation of $n A C h R s$ in the rat cerebellum: association of $\alpha 3$ and $\alpha 4$ subunits. After first clearing the sample with NRS as a control or the $\alpha 4$ antibody, the remaining supernatant was immunoprecipitated with the antibody to the $\alpha 3$ subunit. Inset, Clearing with the $\alpha 4$ antibody did not affect immunoprecipitation by the $\alpha 3$ antibody of $\mathrm{nAChRs}$ in the pineal gland, which are all $\alpha 3$-containing receptors. This experiment served as an additional control for the sequential immunoprecipitation procedure. To confirm these results, the order of antibodies was reversed. That is, after clearing the sample with NRS or the $\alpha 3$ antibody, the resulting supernatant was immunoprecipitated with the $\alpha 4$ antibody. Bars represent the percentage of the total number of $\left[{ }^{3} \mathrm{H}\right] \mathrm{EB}$-labeled $\mathrm{nAChRs}$ immunoprecipitated by the capturing antibody and are the mean \pm SEM of six to nine experiments in the main figure and of three experiments in the inset. The values above the bars are the percentage reduction of total cerebellar $n A C h R s$ resulting from clearing with the indicated antibody compared with the corresponding value after clearing with NRS. Different from corresponding NRS control, ${ }^{*} p<0.05,{ }^{* * *} p<0.001$.

ing that $\sim 20 \%$ of the total heteromeric nAChRs in the cerebellum are $\alpha 4 \beta 4^{\star}$ subtypes (Fig. $6 A$ ).

Again, we then examined the implied subunit associations when the order of antibodies was reversed. The results of these studies are shown in Figure $6 \mathrm{~B}$. After clearing with the $\beta 4$ antibody, the number of heteromeric nAChRs in the cerebellum immunoprecipitated by the $\alpha 3$ and $\alpha 4$ antibodies was decreased by 48 and $22 \%$, respectively. Again, the similarity of the results from the studies shown in Figure 6, $A$ and $B$, reinforces the associations of the $\beta 4$ subunit with $\alpha 3$ and $\alpha 4$ subunits and indicates that $\sim 45 \%$ of the nAChRs in the cerebellum are an $\alpha 3 \beta 4^{\star}$ subtype and $\sim 21 \%$ are an $\alpha 4 \beta 4^{\star}$ subtype.

Together, the initial experiments shown in Figures 5 and 6 indicate the following subunits associations among the heteromeric nAChRs in the cerebellum: $\alpha 3 \beta 2^{*}(\sim 26 \%), \alpha 4 \beta 2^{*}$ $(\sim 54 \%), \alpha 3 \beta 4^{\star}(\sim 45 \%)$, and $\alpha 4 \beta 4^{*}(\sim 21 \%)$. The total number of these subunit associations equals $146 \%$ of the nAChRs in the cerebellum, which is statistically $>100 \%(p<0.01)$. This obvious discrepancy along with the single immunoprecipitation data in Figures 3 and 4 strongly suggests that the cerebellum expresses mixed heteromeric receptors composed of both $\alpha$ subunits and/or both $\beta$ subunits. To test this directly, we examined associations between $\alpha 3$ and $\alpha 4$ subunits and $\beta 2$ and $\beta 4$ subunits.

Associations between the $\alpha 3$ and $\alpha 4$ subunits in the cerebellum Sequential immunoprecipitation studies were performed to determine the extent of association, if any, between the $\alpha 3$ and $\alpha 4$ subunits in nAChRs in the cerebellum. As shown in Figure 7, when the cerebellum extracts were first cleared with NRS, subsequent incubation with the $\alpha 3$ antibody immunoprecipitated $\sim 60 \%$ of the $\left[{ }^{3} \mathrm{H}\right]$ EB-labeled nAChRs. But after clearing with the $\alpha 4$ antibody, the number of nAChRs subsequently immunoprecipitated by the $\alpha 3$ antibody was decreased to $\sim 41 \%$ of the total, indicating that $\sim 19 \%$ of the heteromeric nAChRs in the cerebellum contain both the $\alpha 3$ and $\alpha 4$ subunits. We then reversed the order of the antibodies to confirm this subunit association and 


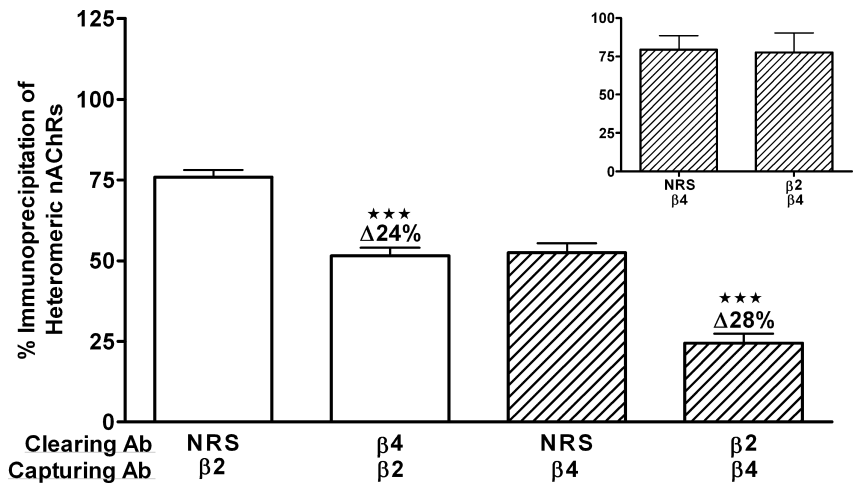

Figure 8. Sequential immunoprecipitation of $\mathrm{nAChRs}$ in the rat cerebellum: association of $\beta 2$ and $\beta 4$ subunits. After first clearing the sample with NRS as a control or the $\beta 4$ antibody, the remaining supernatant was immunoprecipitated with the antibody to the $\beta 2$ subunit. To confirm these results, the order of antibodies was reversed. That is, after clearing the sample with NRS or the $\beta 2$ antibody, the resulting supernatant was immunoprecipitated with the $\beta 4$ antibody. Inset, Control experiment showing that clearing with the $\beta 2$ antibody did not significantly affect immunoprecipitation by the $\beta 4$ antibody of $n A C h R s$ in the pineal gland, which are all $\beta 4$-containing receptors. The bars represent the percentage of the total number of $\left[{ }^{3} \mathrm{H}\right] \mathrm{EB}-$ labeled nAChRs immunoprecipitated by the capturing antibody and are the mean \pm SEM of six to nine experiments in the main figure and of three experiments in the inset. The values above the bars are the percentage reduction of total cerebellar $n A C h R s$ resulting from clearing with the indicated antibody compared with the corresponding value after clearing with NRS. Different from corresponding NRS control, ${ }^{* * *} p<0.001$.

test the precision of this estimate. Figure 7 shows that clearing with the $\alpha 3$ antibody decreased the number of nAChRs subsequently immunoprecipitated by the $\alpha 4$ antibody by $23 \%$ of the total. These data thus support the hypothesis that the cerebellum contains mixed heteromeric nAChRs and indicate that $\sim 21 \%$ of the receptors contain both $\alpha 3$ and $\alpha 4$ subunits (i.e., $\alpha 3 \alpha 4 \beta \mathrm{x}^{\star}$ ).

All of the antibodies used here are highly selective for their cognate subunits, but as an additional control for the sequential immunoprecipitation procedure itself, we also examined the association of these two $\alpha$ subunits in rat pineal gland, in which virtually all of the nAChRs are the $\alpha 3 \beta 4$ subtype (Hernandez et al., 2004). As shown in the inset in Figure 7, the sequential immunoprecipitation procedure did not detect an association between $\alpha 3$ and $\alpha 4$ subunits in this tissue, indicating that the association between these two subunits detected in the cerebellum is unlikely to be an artifact of the procedure.

Associations between the $\beta 2$ and $\beta 4$ subunits in the cerebellum Similar studies were performed to test for an association between the $\beta 2$ and $\beta 4$ subunits in cerebellar nAChRs. Clearing with the $\beta 4$ antibody decreased the total number of cerebellar nAChRs immunoprecipitated with the $\beta 2$ antibody by $\sim 24 \%$ (Fig. 8 ), whereas clearing with the $\beta 2$ antibody decreased the total number of receptors immunoprecipitated with the $\beta 4$ antibody by $\sim 28 \%$ (Fig. 8 ). Again, no evidence of an association between the $\beta 2$ and $\beta 4$ subunits was found in the pineal gland (Fig. 8, inset). These data thus also support the hypothesis that the cerebellum expresses mixed heteromeric nAChRs and indicate that $\sim 26 \%$ of those receptors contain both $\beta 2$ and $\beta 4$ subunits (i.e., $\alpha \times \beta 2 \beta 4^{\star}$ ).

Together, the data in Figures 7 and 8 indicate that the cerebellum expresses $\mathrm{nAChR}$ subtypes that contain $\alpha 3$ subunits in association with $\alpha 4$ subunits, as well as subtypes that contain $\beta 2$ subunits in association with $\beta 4$ subunits. The presence of these mixed heteromeric subtypes explains how the percentage of cerebellar nAChRs immunoprecipitated with the $\alpha 3$ and $\alpha 4$ antibodies and the percentage immunoprecipitated with the $\beta 2$ and $\beta 4$ antibodies can exceed $100 \%$ of the total nAChRs in the cerebellum.

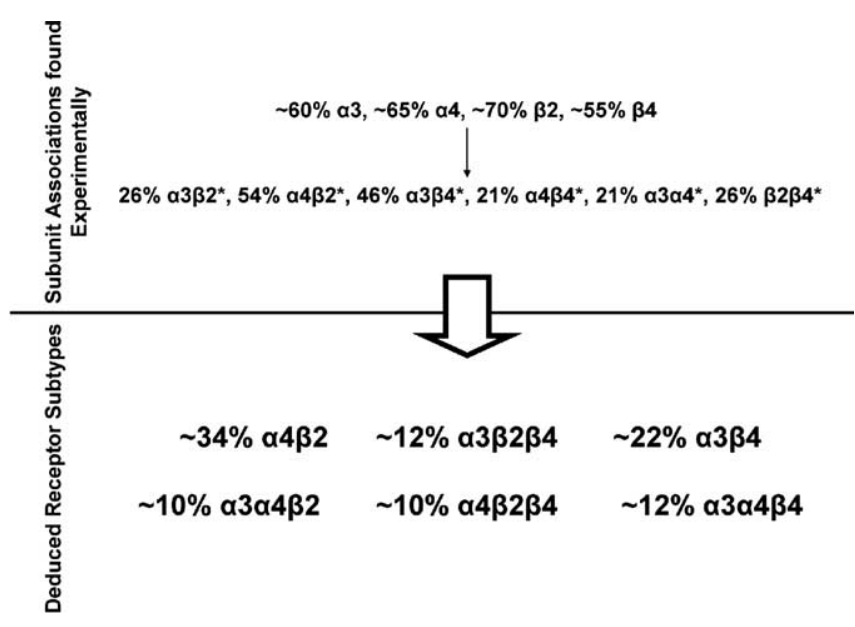

Figure 9. nAChR subunits, subunit associations, and deduced receptor subtypes in the rat cerebellum. Schematic showing experimentally derived data from single immunoprecipitations (row 1) and sequential immunoprecipitations (row 2) and the six deduced receptor subtypes present within the rat cerebellum (see Discussion).

\section{Discussion}

These studies show that the rat cerebellum expresses several subtypes of nAChRs, including mixed heteromeric subtypes that contain $\alpha 3$ subunits in association with $\alpha 4$ subunits and $\beta 2$ subunits in association with $\beta 4$ subunits. Although a previous study reported the presence of $\mathrm{nAChRs}$ containing $\beta 3$ subunits in association with $\beta 4$ subunits in the rat cerebellum (Forsayeth and Kobrin, 1997), we did not find evidence for the $\beta 3$ subunit mRNA or protein in our studies. It is possible that the $\beta 3$ subunit is expressed but at levels below our detection limits.

Figure 9 provides a summary of the subunit associations determined experimentally in our studies and the proposed nAChR heteromeric subtypes that can be deduced from these data. We arrived at these proposed subtype assignments as follows: the single immunoprecipitation studies (Figs. 3, 4) showed that the number of nAChR subtypes containing $\alpha 3$ and $\alpha 4$ subunits as well as the number containing $\beta 2$ and $\beta 4$ subunits were each significantly $>100 \%$ of the nAChRs in the cerebellum. This indicates that some of the receptors contain both $\alpha 3$ and $\alpha 4$ subunits and some contain both $\beta 2$ and $\beta 4$ subunits. The sequential immunoprecipitation data in Figures 5 and 6 indicated that the $\alpha 3 \beta 2^{\star}, \alpha 4 \beta 2^{\star}, \alpha 3 \beta 4^{\star}$, and $\alpha 4 \beta 4^{*}$ subunit associations together add up to $\sim 146 \%$ of the total number of heteromeric nAChRs measured with $\left[{ }^{3} \mathrm{H}\right] \mathrm{EB}$, again supporting the hypothesis that there are mixed heteromeric receptors in the cerebellum. Moreover, the studies that showed an association between $\alpha 3$ and $\alpha 4$ subunits (Fig. 7) and between $\beta 2$ and $\beta 4$ subunits (Fig. 8 ) provide direct evidence for the existence of mixed heteromeric nAChRs.

\section{Subtypes deduced from the $\alpha 3 \alpha 4$ subunit associations}

Our results indicate that $\sim 21 \%$ of the heteromeric nAChRs in the cerebellum contain both $\alpha 3$ and $\alpha 4$ subunits (Fig. 7). Initial immunoprecipitation with the $\alpha 3$ antibody cleared $\sim 43 \%$ of the $\beta 4$ containing receptors but left $\sim 10 \%$ of the receptors that could still be immunoprecipitated by the $\beta 4$ antibody (Fig. $6 A$ ). This $10 \%$ residual population of $\beta 4$-containing receptors presumably represents $\alpha 4 \beta 4^{\star}$ receptors that do not contain $\alpha 3$ subunits. The $\alpha 3 \beta 4^{\star}$ and $\alpha 4 \beta 4^{\star}$ receptor subtypes together appear to comprise $\sim 67 \%$ of the measured heteromeric nAChRs in the cerebellum (Fig. 6), but the $\beta 4$ subunit was found in only $\sim 55 \%$ of the nAChRs (Figs. 3,4 ). This difference is statistically significant $(p<0.01)$ and therefore 
suggests that $\sim 12 \%$ of the $\beta 4$ subunits are associated with both $\alpha 3$ and $\alpha 4$ subunits, yielding an $\alpha 3 \alpha 4 \beta 4^{\star}$ subtype. Because the $\alpha 4 \beta 4$ association also was found in $\sim 21 \%$ of the receptors (Fig. 6 ) and $\sim 12 \%$ can be accounted for by the $\alpha 3 \alpha 4 \beta 4^{*}$ subtype, the remaining $\sim 9 \%$ of the $\alpha 4 \beta 4$ association is consistent with the receptors designated as $\alpha 4 \beta 4^{\star}$ with no $\alpha 3$ that were found as the residual in Figure $6 A$. The $\alpha 3 \beta 2^{*}$ and $\alpha 4 \beta 2^{*}$ subtypes represent $\sim 80 \%$ of the measured nAChRs in the cerebellum (Fig. 5), but the $\beta 2$ subunit was found in only $\sim 70 \%$ of the receptors (Fig. 3 ). This difference is statistically significant $(p<0.01)$ and thus suggests that $\sim 10 \%$ of the $\beta 2$ subunits are associated with both $\alpha 3$ and $\alpha 4$ subunits, which would yield an $\alpha 3 \alpha 4 \beta 2^{\star}$ subtype. This subtype would then account for the remaining $\alpha 3 \alpha 4$ subunit associations. Together, this analysis can account for virtually all of the mixed heteromeric receptors that contain both $\alpha 3$ and $\alpha 4$ subunits and indicates that these appear to be nearly equally divided between $\alpha 3 \alpha 4 \beta 2$ and $\alpha 3 \alpha 4 \beta 4$ subtypes.

\section{Subtypes deduced from the $\boldsymbol{\beta} 2 \boldsymbol{\beta} 4$ subunit associations}

Our measurements indicate that $\sim 26 \%$ of the heteromeric nAChRs in the cerebellum contain both $\beta 2$ and $\beta 4$ subunits (Fig. 8 ). These $\beta 2 \beta 4$ subunit associations also appear to represent two receptor populations, because after clearing with the $\beta 4$ antibody, $\sim 10 \%$ of the $\mathrm{AAChR}$ could still be immunoprecipitated by the $\alpha 3$ antibody (Fig. $6 B$ ). This population represents $\alpha 3 \beta 2^{*}$ receptors that do not contain $\beta 4$ subunits. All of the $\alpha 3 \beta 2^{*}$ subtypes together represent $\sim 26 \%$ of the heteromeric nAChRs in the cerebellum (Fig. 5), and $\sim 10 \%$ of these also contain an $\alpha 4$ subunit (i.e., the $\alpha 3 \alpha 4 \beta 2^{\star}$ subtype derived above). The $\alpha 3 \beta 2^{\star}$ and $\alpha 3 \beta 4^{\star}$ subtypes together appear to comprise $\sim 72 \%$ of the heteromeric nAChRs in the cerebellum (Figs. 5, 6), but the $\alpha 3$ subunit itself was found in only $\sim 60 \%$ of the receptors (Figs. 3, 4). Again, this difference is statistically significant $(p<0.01)$. Together, these data suggest that $\sim 12 \%$ of the $\alpha 3$ subunits associate with both $\beta 2$ and $\beta 4$ subunits, forming an $\alpha 3 \beta 2 \beta 4$ receptor subtype. The $\alpha 4 \beta 2^{\star}$ and $\alpha 4 \beta 4^{\star}$ subtypes together comprise $\sim 75 \%$ of the heteromeric nAChRs in the cerebellum (Figs. 5, 6), but the $\alpha 4$ subunit was found in only $\sim 65 \%$ of the receptors (Figs. 3,4 ). This suggests that $\sim 10 \%$ of the $\alpha 4$ subunit associates with both $\beta 2$ and $\beta 4$ subunits, forming an $\alpha 4 \beta 2 \beta 4$ receptor subtype. Thus, this analysis can account for nearly all of the mixed heteromeric subtypes that contain both $\beta 2$ and $\beta 4$ subunits, and these too appear to be nearly equally divided between $\alpha 3 \beta 2 \beta 4$ and $\alpha 4 \beta 2 \beta 4$ subtypes.

In these analyses, the mixed heteromeric receptors together accounted for $\sim 44 \%$ of the total number of heteromeric nAChRs in the cerebellum; thus, $\sim 56 \%$ would be designated as simple heteromeric subtypes. The $\alpha 4 \beta 2^{\star}$ subtypes together comprised $\sim 54 \%$ of the heteromeric nAChRs in the cerebellum (Fig. 5), and $\sim 20 \%$ of the total population of nAChRs can be accounted for by the two mixed heteromeric subtypes designated as $\alpha 3 \alpha 4 \beta 2$ and $\alpha 4 \beta 2 \beta 4$; therefore, $\sim 34 \%$ of the nAChRs in the cerebellum appear to be the simple heteromeric subtype $\alpha 4 \beta 2$. Similarly, the $\alpha 3 \beta 4^{\star}$ subtypes represent $\sim 46 \%$ of the nAChRs in the cerebellum (Fig. 6), and $\sim 24 \%$ of the total population are accounted for by the two mixed heteromeric subtypes $\alpha 3 \alpha 4 \beta 4$ and $\alpha 3 \beta 2 \beta 4$; thus, $\sim 22 \%$ of the nAChRs in the cerebellum appear to be the simple heteromeric subtype $\alpha 3 \beta 4$. Although the subtype containing all four subunits might exist within the cerebellum, based on analysis of residual values, it would represent a small fraction, below our level of detection.

Together, these analyses indicate that the cerebellum expresses at least six different heteromeric nAChRs, including two simple heteromeric subtypes and four mixed heteromeric subtypes. Interestingly, analysis of heteromeric nAChR subtypes in the granule cell layer of the cerebellum using autoradiography with pharmacological masks indicated that $51 \%$ of the $\left[{ }^{3} \mathrm{H}\right] \mathrm{EB}$ binding sites are an $\alpha 4 \beta 2^{\star}$ subtype and $\sim 49 \%$ are an $\alpha 3 \beta 4^{\star}$ subtype (Perry et al., 2002), values that are close to the combined percentages of simple and mixed heteromeric receptors representing these subtypes found here by immunoprecipitation. Previous data demonstrated that the pharmacology of simple heteromeric $\mathrm{nAChR}$ binding sites reflects primarily the presence of the $\beta 2$ or $\beta 4$ subunit (Parker et al., 1998; Xiao and Kellar, 2004). The current data suggest that the influence of the $\beta$ subunits extends to mixed heteromeric receptors that contain both $\alpha 3$ and $\alpha 4$ subunits, but these data do not allow a good assessment of the pharmacology of the nAChRs containing both $\beta 2$ and $\beta 4$ subunits.

The two simple heteromeric subtypes $\alpha 4 \beta 2$ and $\alpha 3 \beta 4$ appear to account for slightly more than one-half the nAChRs in the rat cerebellum. These receptors are found in abundance in other parts of the rat nervous system. In fact, the $\alpha 4 \beta 2$ subtype is thought to be the predominant heteromeric $\mathrm{nAChR}$ in the rat brain (Whiting et al., 1991; Flores et al., 1992; Perry et al., 2002), and $\alpha 3 \beta 4$ subtypes appear to be the predominant $\mathrm{nAChR}$ in several autonomic nervous system ganglia (for review, see Wang et al., 2002), as well as in the trigeminal ganglia (Flores et al., 1996) and the pineal gland (Hernandez et al., 2004). In addition, $\alpha 3 \beta 4^{\star}$ subtypes exist in relatively high densities in several regions of rodent brain, including the medial habenula, interpeduncular nucleus, brainstem nuclei, subiculum of the hippocampus, and the cerebellum (Marks et al., 1998; Perry et al., 2002; Gahring et al., 2004). In fact, because the $\alpha 3 \beta 4^{\star}$ subtypes represent nearly one-half of the total heteromeric nAChRs in the cerebellum, they might mediate important functions in this brain region, as they do in the medial habenula (Quick et al., 1999) and hippocampus (Clarke and Reuben, 1996; Alkondon and Albuquerque, 2002).

According to our analyses, the rat cerebellum expresses four mixed heteromeric nAChR subtypes: the $\alpha 3 \alpha 4 \beta 2, \alpha 3 \alpha 4 \beta 4$, $\alpha 3 \beta 2 \beta 4$, and $\alpha 4 \beta 2 \beta 4$, with each representing $\sim 10-12 \%$ of the total population of nAChRs. Moreover, several other mixed heteromeric receptor subtypes have been found by similar methods in other neuronal tissues, but to our knowledge, only the $\alpha 3 \beta 2 \beta 4$ subtype has been found in another rat tissue, the retina (Marritt et al., 2005). Together, these studies suggest the existence of an impressive diversity of nAChR subtypes in native tissues.

The cerebellum has a rich network of intrinsic GABA and glutamate pathways essential to its major functions. In addition, it receives substantial innervation by cholinergic, noradrenergic, and serotonergic axons originating in brainstem nuclei. If different nAChR subtypes are associated with these different neurotransmitter pathways, it could provide a basis for fine-tuning the cerebellar signals and even of selectively influencing cerebellar function. For example, human cerebellum expresses these four nAChR subunits as well as the $\alpha 6$ subunit (Graham et al., 2002), and recent autopsy evidence points to the possible involvement of cerebellar nAChRs in developmental disorders such as autism (Lee et al., 2002; Martin-Ruiz et al., 2004). This suggests the importance of determining the $\mathrm{AAChR}$ subtypes and understanding their physiological roles. These receptors might then provide therapeutic targets for such disorders.

\section{References}

Alkondon M, Albuquerque EX (2002) A non-alpha 7 nicotinic acetylcholine receptor modulates excitatory input to hippocampal CA1 interneurons. J Neurophysiol 87:1651-1654.

Bevington PR (1969) Data reduction and error analysis for the physical sciences, pp 58-64. New York: McGraw-Hill.

Champtiaux N, Han ZY, Bessis A, Rossi FM, Zoli M, Marubio L, McIntosh 
JM, Changeux JP (2002) Distribution and pharmacology of $\alpha$ 6-containing nicotinic acetylcholine receptors analyzed with mutant mice. J Neurosci 22:1208-1217.

Clarke PB, Reuben M (1996) Release of [3H]-noradrenaline from rat hippocampal synaptosomes by nicotine: mediation by different nicotinic receptor subtypes from striatal $[3 \mathrm{H}]$-dopamine release. $\mathrm{Br} \mathrm{J}$ Pharmacol 117:595-606.

Conroy WG, Berg DK (1998) Nicotinic receptor subtypes in the developing chick brain: appearance of a species containing the alpha4, beta2, and alpha5 gene products. Mol Pharmacol 53:392-401.

Conroy WG, Vernallis AB, Berg DK (1992) The alpha 5 gene product assembles with multiple acetylcholine receptor subunits to form distinctive receptor subtypes in brain. Neuron 9:679-691.

Court JA, Martin-Ruiz C, Graham A, Perry E (2000) Nicotinic receptors in human brain: topography and pathology. J Chem Neuroanat 20:281-298.

Cui C, Booker TK, Allen RS, Grady SR, Whiteaker P, Marks MJ, Salminen O, Tritto T, Butt CM, Allen WR, Stitzel JA, McIntosh JM, Boulter J, Collins AC, Heinemann SF (2003) The $\beta 3$ nicotinic receptor subunit: a component of $\alpha$-conotoxin MII-binding nicotinic acetylcholine receptors that modulate dopamine release and related behaviors. J Neurosci 23:11045-11053.

De Filippi G, Baldwinson T, Sher E (2001) Evidence for nicotinic acetylcholine receptor activation in rat cerebellar slices. Pharmacol Biochem Behav 70:447-455.

Flores CM, Rogers SW, Pabreza LA, Wolfe BB, Kellar KJ (1992) A subtype of nicotinic cholinergic receptor in rat brain is composed of alpha 4 and beta 2 subunits and is up-regulated by chronic nicotine treatment. Mol Pharmacol 41:31-37.

Flores CM, DeCamp RM, Kilo S, Rogers SW, Hargreaves KM (1996) Neuronal nicotinic receptor expression in sensory neurons of the rat trigeminal ganglion: demonstration of $\alpha 3 \beta 4$, a novel subtype in the mammalian nervous system. J Neurosci 16:7892-7901.

Forsayeth JR, Kobrin E (1997) Formation of oligomers containing the $\beta 3$ and $\beta 4$ subunits of the rat nicotinic receptor. J Neurosci 17:1531-1538.

Gahring LC, Persiyanov K, Dunn D, Weiss R, Meyer EL, Rogers SW (2004) Mouse strain-specific nicotinic acetylcholine receptor expression by inhibitory interneurons and astrocytes in the dorsal hippocampus. J Comp Neurol 468:334-346.

Girod R, Role LW (2001) Long-lasting enhancement of glutamatergic synaptic transmission by acetylcholine contrasts with response adaptation after exposure to low-level nicotine. J Neurosci 21:5182-5190.

Graham A, Court JA, Martin-Ruiz CM, Jaros E, Perry R, Volsen SG, Bose S, Evans N, Ince P, Kuryatov A, Lindstrom J, Gotti C, Perry EK (2002) Immunohistochemical localization of nicotinic acetylcholine receptor subunits in human cerebellum. Neuroscience 113:493-507.

Granon S, Faure P, Changeux JP (2003) Executive and social behaviors under nicotinic receptor regulation. Proc Natl Acad Sci USA 100:9596-9601.

Hernandez SC, Vicini S, Xiao Y, Davila-Garcia MI, Yasuda RP, Wolfe BB, Kellar KJ (2004) The nicotinic receptor in the rat pineal gland is an alpha3beta4 subtype. Mol Pharmacol 66:978-987.

Houghtling RA, Dávila-Garcia MI, Kellar KJ (1995) Characterization of $( \pm)\left[{ }^{3} \mathrm{H}\right]$ epibatidine binding to nicotinic cholinergic receptors in rat and human brain. Mol Pharmacol 48:280-287.

Lee M, Martin-Ruiz C, Graham A, Court J, Jaros E, Perry R, Iversen P, Bauman M, Perry E (2002) Nicotinic receptor abnormalities in the cerebellar cortex in autism. Brain 125:1483-1495.

Lindstrom J (1997) Nicotinic acetylcholine receptors in health and disease. Mol Neurobiol 15:193-222.

Mansvelder HD, McGehee DS (2002) Cellular and synaptic mechanisms of nicotine addiction. J Neurobiol 53:606-617.

Marks MJ, Smith KW, Collins AC (1998) Differential agonist inhibition identifies multiple epibatidine binding sites in mouse brain. J Pharmacol Exp Ther 285:377-386.

Marritt AM, Cox BC, Yasuda RP, McIntosh M, Xiao Y, Wolfe BB, Kellar KJ (2005) Nicotinic cholinergic receptors in the rat retina: simple and mixed heteromeric subtypes. Mol Pharmacol, in press.

Martin-Ruiz CM, Lee M, Perry RH, Baumann M, Court JA, Perry EK (2004) Molecular analysis of nicotinic receptor expression in autism. Brain Res Mol Brain Res 123:81-90.

Moretti M, Vailati S, Zoli M, Lippi G, Riganti L, Longhi R, Viegi A, Clementi F, Gotti C (2004) Nicotinic acetylcholine receptor subtypes expression during rat retina development and their regulation by visual experience. Mol Pharmacol 66:85-96.

Mukhin AG, Gundisch D, Horti A, Koren AO, Tamagnan G, Kimes AS, Chambers J, Vaupel DB, King SL, Picciotto MR, Innis RB, London ED (2000) 5-Iodo-A-85380, an $\alpha_{4} \beta_{2}$ subtype-selective ligand for nicotinic acetylcholine receptors. Mol Pharmacol 57:642-649.

Nakayama H, Shioda S, Nakajo S, Ueno S, Nakai Y (1998) Expression of the nicotinic acetylcholine receptor alpha4 subunit mRNA in the rat cerebellar cortex. Neurosci Lett 256:177-179.

O'Leary KT, Leslie FM (2003) Developmental regulation of nicotinic acetylcholine receptor-mediated $[3 \mathrm{H}]$ norepinephrine release from rat cerebellum. J Neurochem 84:952-959.

Parker MJ, Beck A, Luetje CW (1998) Neuronal nicotinic receptor beta2 and beta4 subunits confer large differences in agonist binding affinity. Mol Pharmacol 54:1132-1139.

Perry DC, Xiao Y, Nguyen HN, Musachio JL, Davila-Garcia MI, Kellar KJ (2002) Measuring nicotinic receptors with characteristics of alpha4beta2, alpha3beta2 and alpha3beta4 subtypes in rat tissues by autoradiography. J Neurochem 82:468-481.

Perry EK, Lee ML, Martin-Ruiz CM, Court JA, Volsen SG, Merrit J, Folly E, Iversen PE, Bauman ML, Perry RH, Wenk GL (2001) Cholinergic activity in autism: abnormalities in the cerebral cortex and basal forebrain. Am J Psychiatry 158:1058-1066.

Quick MW, Ceballos RM, Kasten M, McIntosh JM, Lester RA (1999) Alpha3beta4 subunit-containing nicotinic receptors dominate function in rat medial habenula neurons. Neuropharmacology 38:769-783.

Reno LA, Zago W, Markus RP (2004) Release of [(3)H]-L-glutamate by stimulation of nicotinic acetylcholine receptors in rat cerebellar slices. Neuroscience 124:647-653.

Rogers SW, Mandelzys A, Deneris ES, Cooper E, Heinemann S (1992) The expression of nicotinic acetylcholine receptors by PC12 cells treated with NGF. J Neurosci 12:4611-4623.

Rossi DJ, Hamann M, Attwell D (2003) Multiple modes of GABAergic inhibition of rat cerebellar granule cells. J Physiol (Lond) 548:97-110.

Vailati S, Moretti M, Longhi R, Rovati GE, Clementi F, Gotti C (2003) Developmental expression of heteromeric nicotinic receptor subtypes in chick retina. Mol Pharmacol 63:1329-1337.

Vernallis AB, Conroy WG, Berg DK (1993) Neurons assemble acetylcholine receptors with as many as three kinds of subunits while maintaining subunit segregation among receptor subtypes. Neuron 10:451-464.

Wang N, Orr-Urtreger A, Korczyn AD (2002) The role of neuronal nicotinic acetylcholine receptor subunits in autonomic ganglia: lessons from knockout mice. Prog Neurobiol 68:341-360.

Whiting P, Lindstrom J (1987) Purification and characterization of a nicotinic acetylcholine receptor from rat brain. Proc Natl Acad Sci USA 84:595-599.

Whiting P, Schoepfer R, Lindstrom J, Priestley T (1991) Structural and pharmacological characterization of the major brain nicotinic acetylcholine receptor subtype stably expressed in mouse fibroblasts. Mol Pharmacol 40:463-472.

Winzer-Serhan UH, Leslie FM (1997) Codistribution of nicotinic acetylcholine receptor subunit alpha3 and beta4 mRNAs during rat brain development. J Comp Neurol 386:540-554.

Wonnacott S (1997) Presynaptic nicotinic ACh receptors. Trends Neurosci 20:92-98.

Xiao Y, Kellar KJ (2004) The comparative pharmacology and up-regulation of rat neuronal nicotinic receptor subtype binding sites stably expressed in transfected mammalian cells. J Pharmacol Exp Ther 310:98-107.

Xiao Y, Meyer EL, Thompson JM, Surin A, Wroblewski J, Kellar KJ (1998) Rat alpha3/beta4 subtype of neuronal nicotinic acetylcholine receptor stably expressed in a transfected cell line: pharmacology of ligand binding and function. Mol Pharmacol 54:322-333.

Yeh JJ, Yasuda RP, Davila-Garcia MI, Xiao Y, Ebert S, Gupta T, Kellar KJ, Wolfe BB (2001) Neuronal nicotinic acetylcholine receptor alpha3 subunit protein in rat brain and sympathetic ganglion measured using a subunit-specific antibody: regional and ontogenic expression. J Neurochem 77:336-346.

Zhang X, Liu C, Miao H, Gong ZH, Nordberg A (1998) Postnatal changes of nicotinic acetylcholine receptor alpha 2 , alpha 3 , alpha 4 , alpha 7 and beta 2 subunits genes expression in rat brain. Int J Dev Neurosci 16:507-518.

Zoli M, Moretti M, Zanardi A, McIntosh JM, Clementi F, Gotti C (2002) Identification of the nicotinic receptor subtypes expressed on dopaminergic terminals in the rat striatum. J Neurosci 22:8785-8789. 